\title{
Los prejuicios jurídicos al silogismo: una confusión entre forma y
} contenido

\section{Legal prejudices to sylogism. A confusion between form and conent}

\author{
Gregorio Posada Ramírez*, Federico Duque del Río**, María Angélica \\ Ortiz Salazar***
}

\begin{abstract}
*Profesor Asociado de la Universidad del Quindío. Miembro del grupo de investigación Razones y Acciones de esta misma universidad. Correo electrónico gposada@uniquindio.edu.co.

** Vicerrector (e) Universidad La Gran Colombia Seccional Armenia, viceacad@ugca.edu.co

*** Directora de investigaciones Universidad La Gran Colombia dirinvestigaciones@ugca.edu.co, miembro del grupo de investigación Paideia.
\end{abstract}

Cómo citar: Posada, G., Duque, F., Ortiz, M.A(2016). Los prejuicios jurídicos al silogismo: una confusión entre forma y contenido. Inciso 18 (1) 109-120.

http://dx.doi.org/10.18634/incj.18v.1i.588

Recibido:11/04/2016 Revisado: 26/05/2016 Aceptado: 17/06/2016

\section{Resumen}

Este texto argumenta que algunos de los prejuicios y prevenciones al uso del silogismo jurídico, como forma de razonar o tomar decisiones jurídicas, obedece a una confusión en la comprensión de lo que es un razonamiento silogístico. Independientemente de la actitud con la que se asuma el orden jurídico, ya sea como un conjunto de normas a las que se debe incontrovertiblemente obedecer, o como el progresivo intento humano de conducir las acciones de las personas hacia la justicia, el uso del silogismo jurídico no condena a la religiosidad incontrovertible de las normas, y no castra los ideales de justicia propios del derecho. Para mostrar esto, se ubicará las críticas del silogismo jurídico en el contexto de la discusión positivismo jurídico vs iusnaturalismo jurídico. Se describirá lo que son los razonamientos silogísticos, y cómo estos, una vez incorporados dentro del ámbito jurídico, se especifican como silogismos jurídicos. Finalmente, se argumentará que la censura al silogismo como forma de argumentación jurídica, obedece a la incapacidad de distinguir entre forma y contenido de los argumentos. El uso del silogismo dentro del campo derecho es promisorio, pues es una estructura válida del pensamiento, un esquema de razonamiento eficaz que no es exclusivo de una doctrina o ideología del derecho.

Palabras clave: Derecho, proposición, argumento, silogismo, lógica.
This text holds that some of the prejudices and preventions to the use of legal syllogism, as the way of reasoning or making legal decisions, result from a confusion in comprehension of what a syllogistic reasoning is. Independently from the attitude which the legal order is assumed with, either as a group of standards that should uncontrovertibly be obeyed, or as the progressive human attempt of leading the individual actions toward justice, the use of syllogism does not condemn the incontrovertible religiosity of standards, and does not enervate the ideals of justice embodied in the law. To show this fact, critics to legal syllogism will be located within the context of legal positivism vs legal iusnaturalism discussion. Syllogistic reasoning will be described, and how such reasoning, once included within the legal scope, is specified as legal syllogisms. Finally, it will be debated that censure to syllogism as a way of legal argumentation, comes from the inability to distinguish between form and content of argumentations. Syllogism use in the field of law is promissory, since it is a valid structure of thought, a scheme of effective reasoning which is not exclusive of a doctrine or ideology of the law.

Keywords: Argument, low, logic, proposition, syllogism 
Iusnaturalismo frente a positivismo jurídico: la naturaleza intrínseca del derecho

La discusión acerca de la naturaleza intrínseca del derecho se ha presentado históricamente a partir de la controversia iusnaturalismo contra positivismo jurídico. Desde el interés de encontrar una definición universal y necesaria de lo que es esta disciplina, puntos de vista opuestos de importantes filósofos y juristas han recreado una interesante lucha de las ideas sobre lo que esta pueda ser. Las lúcidas y persuasivas razones de ambas partes hacen indecidible concluyentemente quién debería ceder y quién debería alzar su definición de lo qué es el derecho. Podría decirse que hasta los cuervos graznan en los tejados sobre cuál es su rasgo esencial, y desde hace más de 200 años lo hacen, porque como bien lo anota Emil Lask en su libro Filosofía Jurídica (2008), esta discusión bien pudo partir desde Inmmanuel Kant. Cuando el filósofo de Konigsberg aceptó que el derecho es la regulación de la conducta humana a partir de la coacción exterior, algunos lo entendieron como el perfeccionamiento de la vida moral en comunidad: los ahora llamados iusnaturalistas; otros como la obediencia a las instituciones, que en tanto reguladores externos, deben dirigir incontrovertiblemente la vida en sociedad de las personas: los hoy reconocidos positivistas jurídicos.

Sin ir siglos atrás, en El problema del positivismo jurídico (1997) de Norberto Bobbio puede encontrarse una síntesis de esta indisoluble discusión. Para los iusnaturalistas la característica esencial del derecho es el ideal de justicia, para los positivistas la esencia es el seguimiento de las normas. Si bien, ambos consideran importante lo acentuado y defendido por el bando opuesto, en tanto lo asumen como relevante pero no intrínsecamente esencial, no lo toman como definitivo para el derecho. Así, para los positivistas jurídicos obedecer de las normas, independientemente de su valoración como justas o injustas, es el rasgo esencial. No obstante, si se les exige una consideración sobre la justicia seguir las normas, obedecer las leyes es para ellos lo justo. Esto porque la justicia está supeditada al cumplimiento de las normas. Las leyes o las normas son para los positivistas jurídicos el rasgo esencial del derecho. Hans Kelsen en ¿Qué es la teoría pura del derecho? dice que desde el estudio lógico de esta disciplina se: "Obtiene el concepto fundamental de todo conocimiento jurídico: el concepto de norma que afirma que algo, o más exactamente una determinada conducta humana, debe de ser” (Kelsen, 1998:9).

Por otra parte, para los iusnaturalistas solo deben seguirse las normas en tanto sean afines con la justicia y los ideales morales de bien. Una norma que en virtud, por ejemplo, de la falibilidad humana implique la legalidad de acciones notoriamente injustas, no debería obedecer por mor del derecho mismo, pues las leyes deben estar al servicio de la justicia. Para los iusnaturalistas la justicia y los ideales morales se levantan sobre las normas, son la esencia del derecho. Norberto Bobbio en El problema del positivismo jurídico (1997) señala que para los iusnaturalistas la base del derecho es: "El conjunto de los primeros principios éticos, muy generales, de los cuales el legislador humano debe de tomar su inspiración para la formulación de reglas de derecho positivo" (Bobbio, 1997:70).

Decidir si la esencia del derecho es la ley o es la justicia pasa más por una actitud frente al derecho, y en buena medida, ante la vida, que por una decisión de argumentos. Ambas posiciones incorporan intuiciones muy profundas, no solo sobre la naturaleza del derecho, sino también sobre la condición humana. Ante una tensión entre intuiciones básicas, más que argumentos es el temperamento el que decide hacia qué bando tender, como dice el proverbio chino: "Es más fácil vaciar un río que el carácter de un hombre". Por lo que, esperar una solución o cuando menos, una disolución de la controversia es tanto como querer vaciar un río. No obstante, aunque la discusión iusnaturalismo contra positivismo jurídico es como la mayoría de los problemas filosóficos una controversia insoluble, la que además solo tiene una injerencia tangencial dentro del ejercicio práctico y corriente del derecho, es muy fértil en tanto revela cualidades propias de esta práctica humana y del temple de sus usuarios, entre ellas, su dependencia hacia el razonamiento lógico y metódico, y a su vez, la filiación humana a ideales metafísicos.

En Teoría general del derecho y como una manera de recoger el aspecto esencial del positivismo jurídico, y a su vez, de la existencia humana, Norberto Bobbio muestra cómo la vida de las personas está 
esencialmente determinada por el seguimiento de normas. $\mathrm{Al}$ respecto dice:

\begin{abstract}
Nuestra vida se desenvuelve dentro del mundo de las normas. Creemos ser libres, pero en realidad estamos encerrados en una tupídisima red de reglas de conducta, que desde el nacimiento hasta la muerte dirigen nuestras acciones en esta o aquella dirección. La mayor parte de estas normas se han vuelto tan comunes y ordinarias que ya no nos damos cuenta de su presencia. Pero si observamos un poco desde fuera el desarrollo de la vida de un hombre a través de la actividad educadora que ejerce sobre él sus padres, maestros, etc., nos damos cuenta de que ese hombre se desarrolla bajo la guía de reglas de conducta. (Bobbio, 2007: 3).
\end{abstract}

La inclinación de algunos actores jurídicos por la obediencia incuestionable a las normas, no pasa necesaria y exclusivamente por ser un asunto de moda académica o de aceptación de una tendencia de formación profesional. La devoción a las normas puede tener un origen más fundamental. Lazos con experiencias primogénitas, adhesiones a algún tipo de ideologías, cierta visión de mundo predispone la acogida al punto de vista del positivismo jurídico. Por lo que, la fuerza de aceptación con que algunos asumen las ideas del positivismo jurídico, no es simplemente una cuestión de apego teórico o bibliográfico, convoca fundamentalmente el talante y la actitud con la que se asume la práctica del derecho, y por qué no, hasta la vida misma.

Otro tanto puedo decirse de la posición del derecho defendida por el iusnaturalismo. Cierta inclinación a la metafísica, esto es, la adherencia del pensamiento no solo a ideas justificables empírica y factualmente, sino especialmente a aquellas que van más allá de la experiencia, como son las nociones de justicia, bienes morales o Dios también está arraigada en la naturaleza humana y se afinca más en unas personas que en otras. Immanuel Kant en la Crítica de la razón pura dice:

La razón humana tiene el destino singular, en uno de sus campos de conocimiento, de hallarse acosada por cuestiones que no es capaz de rechazar por ser planteadas por la misma naturaleza de la razón, pero a las que tampoco puede responder por sobrepasar todas sus facultades. -Más adelante continúa- Comienza con principios cuyo uso es inevitable en el curso de la experiencia, uso que se haya a la vez, suficientemente justificado por esta misma experiencia. Con tales principios la razón se eleva cada vez más (como exige su propia naturaleza), llegando a condiciones progresivamente más remotas. Pero, advirtiendo que de esta forma su tarea ha de quedar inacabada, ya que las cuestiones nunca se agotan, se ve obligada a recurrir a principios que sobrepasan todo posible uso empírico y que parecen, no obstante, tan libres de sospecha, que la misma razón ordinaria se halla de acuerdo con ellos. (2006: 9).

A pesar de que se regule con buenas razones lo permisible, y se consensue y exprese a través de leyes y normas, el deseo humano de siempre querer preguntarse constantemente lo fuerza a hender las normas que lo gobiernan. La justicia, como un ideal metafísico, siempre está más allá de lo aprehensible por el hombre. En la búsqueda sin término que es la vida humana, ideales como la justicia, la bondad, la libertad, Dios estimulan la creación de teorías o instituciones que se espera los contenga o represente. Pero como ideales, estas nociones siempre sobrepasan lo humanamente abarcable. Por lo que, más que la sumisión a las teorías e instituciones que regulan la conducta humana, lo que existe es una constante la revisión de ellas, siempre con la ilusión de dar un paso más, uno que nos acerque a las aspiraciones e ideales metafísicos, que como la justicia, son inherentes en el hombre. Así, tan intrínseca a la naturaleza humana como son las normas, lo es su disposición a la metafísica: a pensar e intentar alcanzar ideales que están más allá de lo humanamente asequible, como es el ideal metafísico de la justicia.

Resumiendo, en tanto en el positivismo jurídico y el iusnaturalismo corren dos linajes de la naturaleza humana -el seguimiento de normas y la propensión a ideales metafísicos, estirpes que no son siempre mutuamente incluyentes- la discusión positivismo jurídico contra iusnaturalismo no pasa por ser un debate que se pueda resolver en la arena de la argumentación, pues evoca inclinaciones y afectos inherentes a la naturaleza humana.

Para Norberto Bobbio (1997) la intratable posibilidad de solución al conflicto positivismo jurídico-iusnaturalismo puede presentarse como el desgarramiento de dos elementos sustanciales de la educación occidental: la ciencia y la moralidad. 
Por un lado, el espíritu científico conduce a aceptar únicamente aquello controlable en reglas de justificación empírica y validez lógica, por otro lado, el compromiso como la moralidad, conduce a tener en alta consideración la complejidad de la vida de las personas y su imposibilidad de limitarla en fórmulas o cálculos racionales. El deseo de universalidad del hombre: la ciencia, y la consciencia de su carácter singular, voluble y complejo: lo moral, están en el corazón del conflicto. Así, la necesaria formación científica y objetiva de una profesión hace a los hombres de derecho positivistas jurídicos, y su también necesario compromiso como la moral, los hace iusnaturalistas. Las tensiones históricas entre ciencia y moralidad, entre la disposición humana de generalizar a través de teorías y el compromiso por querer entender las acciones del otro, a través de la capacidad de ponerse en su lugar para recrear sus emociones y vivencias, hace difícil superar la controversia iusnaturalismo positivismo jurídico. $\mathrm{Si}$ a esto sumamos, como señala Vélez Medina (2014), la existencia de la pluralidad de ideales que la formación educativa toma para la educación superior, en la que: "Esta academia que empieza a surgir, tiene la misión ya no de buscar la verdad, sino de acoger diversas concepciones del bien, propiciar escenarios de interpretación del mundo" (2014: 83), al debate positivismo jurídico- iusnaturalismo no debería exigirles un ganador y un perdedor.

Como se mencionó, la controversia no ha sido una discusión bizantina. A pesar de que no se podrá saber cuál es el sexo de los ángeles, se han alcanzado réditos en la búsqueda de definir cuál es el sentido esencial del derecho. Uno de ellos, y que es promisorio para el propósito central de este texto, puede leerse en la fuerte posición que tomó Hans Kelsen en la discusión. Independiente de si la esencia del derecho son las normas o la justicia, en tanto es un tipo especial de conocimiento, el derecho es proposicional, en otras palabras, el derecho es un sistema de enunciados y proposiciones. El saber jurídico es un conjunto de proposiciones que deben restringirse a la regulación lógica y racional a la que todas las proposiciones están condicionadas. Animado por el espíritu del positivismo filosófico y la discusión de lo qué es el derecho, los sistemas jurídicos se asumieron no solo como una forma de regulación de la conducta humana, sino también como un tipo de conocimiento al que debía exigírsele ciertos criterios de cientificidad y rigor en su cuerpo teórico. Dentro de ellos se destaca la asunción a que es un sistema de proposiciones evaluables lógica y críticamente. Dice Bobbio:

\begin{abstract}
No se habla de ciencia jurídica como ciencia formal en el sentido más estricto y riguroso de la palabra, según el cual se distinguen las ciencias formales (como la lógica) de las ciencias empíricas (como la biología); se habla en un sentido más amplio como la forma de saber que no tiene por objeto hechos del mundo físico o humano, sino calificaciones normativas de hechos cuya tarea no es la explicación propiamente de las ciencias naturales, sino la construcción, y en última instancia, el sistema. (Bobbio, 1997: 23).
\end{abstract}

Tanto para positivistas como para iusnaturalistas, decir que el derecho es un sistema de proposiciones, independientemente de si la justificación o motivación de este es empírico o metafísico, significa un avance en el análisis del estudio del derecho. La comprensión de que el derecho subsume, actos, sucesos o relaciones sociales dentro de un sistema conceptual, específicamente, un sistema conceptual jurídico, es una afirmación aceptada sin distingos dentro de ambas posiciones. Por esto, tanto para los positivistas jurídicos como para iusnaturalistas el estudio de las proposiciones y sus relaciones de implicación y justificación es de primera relevancia para la comprensión de lo que es del derecho. El profesor Carlos Alberto Agudelo en su artículo $E l$ uso de la palabra derecho: Un ataque a la práctica del silogismo judicial (2008) señala que las normas jurídicas no son proposiciones que describan empíricamente el mundo. No obstante, una vez constituido un sistema jurídico, existen proposiciones que describen esa región del mundo, que aunque no es empírica o material es real. Pues es una realidad conformada, entre otras cosas, por normas. Dice: "El mundo de los hechos se describe con el mundo de las proposiciones, el mundo de las normas jurídicas se describe con el mundo de las proposiciones jurídicas que hablan de este derecho." (p.77).

En este punto, y enunciando el objetivo central de este trabajo, mostrar que el silogismo jurídico es fecundo para la práctica argumentativa del derecho, independientemente si se asume una actitud positivista o iusnaturalista, puede verse un importante lugar de encuentro del positivismo y el iusnaturalismo. Para 
ambos enfoques el análisis de las proposiciones y sus relaciones es materia esencial del estudio del derecho.

En lo que sigue, y teniendo como objetivo explicar lo que es el silogismo jurídico, se hará una descripción de lo qué son las proposiciones. Adelantándonos un poco, dos cosas pueden afirmarse de ellas. La primera, el sistema jurídico, en tanto saber, es una estructura teórica conformada por proposiciones, así estas son las unidades mínimas que en su conjunción permiten la conformación de las teorías y normas del derecho; la segunda, el silogismo jurídico como forma prototípica del razonamiento jurídico, está conformado por proposiciones, de ahí que, ellas sean los componentes básicos de los razonamientos jurídicos. Así, el conocimiento de lo que son las proposiciones permite comprender el derecho, en tanto saber teórico, y a su vez, permite entenderlo en tanto práctica racional y argumentativa.

\section{Proposiciones y argumentos}

Una cosa es decir: "Carlos Gaviria Díaz nació en Antioquia el 8 de mayo de 1937", otra decir: "Somos tiempo. Somos la famosa parábola de Heráclito el Oscuro. Somos el agua, no el diamante duro, la que se pierde, no la que reposa." (Borges, 2013:592). Y finalmente, una tercera es decir: "Tiene que usar la puerta lateral para salir del teatro". Decimos que estas tres formas de expresiones del lenguaje son cosas: la primera una descripción, la segunda un poema y la tercera una orden. El lenguaje es un instrumento y como bien lo anota el filósofo del lenguaje John Austin, hacemos cosas con palabras (1962). Con el lenguaje se puede informar sobre el mundo: uso descriptivo; expresar nuestros puntos de vistas íntimos y subjetivos: uso emotivo; o hacer mandatos para regular y determinar las acciones humanas: uso prescriptivo. Usar el lenguaje no es algo tan trivial o intrascendente como muchas veces se cree. Cuando los seres humanos hablan hacen cosas en el mundo, algunas incluso tan trágicas que implican la muerte de personas, como cuando un gobierno le declara la guerra a otro, o tan radiantes como cuando un hombre le expresa a su novia la intención de casarse con ella y esta le dice sí.

Entender el lenguaje como un instrumento con el que se hacen cosas, le permite a sus estudiosos ofrecer una imagen más aguda y específica de la manera cómo la especie humana ocupa su lugar en el mundo. El filósofo del lenguaje Ludwig Wittgenstein afirma en su libro póstumo Investigaciones filosóficas: "Imaginar un lenguaje significa imaginar una forma de vida" (1988: 31). El ser humano hace ciencia para describir a través del lenguaje la tierra y el universo; poetiza su vida, exteriorizando a través de palabras la manera cómo íntimamente contempla la existencia, u ordena a través de enunciados que expresan mandatos, la manera cómo deben comportarse las personas. La búsqueda de la verdad, en el caso de la ciencia, de lo bello en el lenguaje poético, y de las acciones buenas para los mandatos, se pueden postular como los principios rectores de estos usos del lenguaje y del modo de estar el hombre en el mundo.

En el caso de las proposiciones, estas son el significado de las expresiones lingüísticas que se usan para describir la realidad. Asimismo, son el significado de las cosas que están hechas con palabras y que buscan presentar conceptualmente los hechos. Decir: "Carlos Gaviria Díaz nació en Antioquia el 8 de mayo de 1937" es emitir un enunciado que describe un hecho del mundo. Este convoca la existencia de Carlos Gaviria, de un lugar en el espacio: Antioquia, y de un momento del tiempo: 8 de mayo de 1937 . Es importante distinguir las proposiciones de los enunciados lingüísticos que las expresan. Si bien las proposiciones se presentan, se hacen públicas a través de los enunciados, ellas y estos son distintos. Los enunciados son físicos, las proposiciones no. Ya sea como ondas sonoras, como trazos de tinta, o como el color negro que está sobre esta página blanca, los enunciados a diferencia de las proposiciones son cosas materiales. Las proposiciones son el significado de los enunciados, son lo que los enunciados trasmiten públicamente. Así como la bandera de Colombia representa públicamente a Colombia, sin que ese objeto físico que pende de una asta sea propiamente Colombia, los enunciados simbolizan o representan proposiciones, sin que los enunciados sean lo mismo que las proposiciones. La manera como los lógicos suelen distinguir entre enunciados y proposiciones es mostrando que enunciados distintos, trazos de tinta diferentes $u$ ondas sonoras distintas, pueden significar una misma proposición. "Antioquía, 8 de mayo de 1937, fue el lugar y la fecha del nacimiento de Carlos Gaviria" es un enunciado distinto a "Carlos Gaviria 
Díaz nació en Antioquia el 8 de mayo de 1937”, sin embargo, significan la misma proposición.

Otro de los rasgos distintivos de las proposiciones es que se evalúan como verdaderas o como falsas. Thomas Hobbes en el Leviatán dice: "Porque la verdad y la falsedad son atributos del lenguaje, no de las cosas. Y donde no hay lenguaje no hay tampoco verdad ni falsedad. la verdad es el lenguaje." (1994: 26) Con lo que el lenguaje es condición necesaria para la existencia de la verdad. En la era de los dinosaurios, época en la que no existía lo que hoy propiamente llamamos lenguaje, no había ni verdad ni falsedad. En tanto no existían esas cosas hechas con palabras y que describen hechos, no había ni verdad ni falsedad. Parafraseando a Hobbes, las proposiciones son la casa de la verdad y de la falsedad, pues son estas las que realmente se evalúan como verdaderas o como falsas. La proposición contenida en el enunciado: "Carlos Gaviria Díaz nació en Antioquia el 8 de mayo de 1937" es verdadera, porque se ajusta a los hechos que describe. En el caso de que el enunciado significará una proposición como que "Carlos Gaviria nació en Armenia el 3 de enero de 1999", sería falsa porque no se ajusta a los hechos.

Adicional a lo anterior, las proposiciones son el resultado de la capacidad humana de afirmar o negar que las cosas tienen o no tienen ciertas propiedades. Afirmar o negar es tener una proposición. Afirmar: "Colombia es un Estado social de derecho" es hacer una descripción del mundo, en la que se asevera que Colombia tiene la propiedad, porta la cualidad de ser un Estado social de derecho; hay un algo, Colombia, del que se afirma otro algo: es un Estado social de derecho. Decir: "La Constitución es norma de normas" es también hacer una afirmación en la que se expresa que una cosa: la Constitución, tiene una propiedad: ser norma de normas. A través de las proposiciones se afirma o niega propiedades o cualidades de las cosas.

Sintetizando, las proposiciones pertenecen a la clase de cosas hechas con el lenguaje, específicamente, al conjuntodeenunciadosquepresentanconceptualmente modos de ser de la realidad. Si bien, las proposiciones están en los enunciados, es importante distinguir entre enunciados y proposiciones. Las proposiciones son el significado de los enunciados descriptivos, y estos, son la manera física y pública en que se presentan las proposiciones. Las proposiciones se evalúan como verdaderas o falsas. Si se ajustan a los hechos son verdaderas, en caso contrario son falsas. Finalmente, a través de ellas se afirman o se niegan propiedades o cualidades de las cosas.

En la sentencia C-221 de 1994, la Corte Constitucional colombiana afirmó que: son inexequibles las sanciones penales para aquellos que porten la dosis personal de estupefacientes para consumo propio. En otras palabras, Carlos Gaviria, el ponente de la sentencia aseveró que no debe penalizarse el porte de dosis personal de marihuana, cocaína, u otro estupefaciente. Varios enunciados, y con ellos, varias proposiciones, se contienen en la afirmación de Carlos Gaviria: la primera: "No debe penalizarse el porte de dosis personal de marihuana"; la segunda: "No debe penalizarse el porte de dosis personal de cocaína"; la tercera: "No debe penalizarse el porte de dosis personal de estupefacientes". Las proposiciones que aseveró Carlos Gaviria, y otras, por ejemplo, que un hombre puede aseverar en caso de que un policía quiera detenerlo por portar menos de veinte gramos de marihuana -que es en Colombia la dosis personal de este psicoactivo- son proposiciones que obtienen su calidad de afirmación aceptable, en razón a que son apoyadas por otras proposiciones.

Como se mencionó, tener una proposición es afirmar algo de algo. Muchas de las afirmaciones que se dan en las proposiciones están motivadas por la aceptación de otras proposiciones. Así, en tanto se acepta que otras proposiciones son verdaderas, pongamos por caso, (p) y (q), y tenemos que (r) es una proposición que es consistente con (p) y (q) entonces se afirma la proposición (r). Por ejemplo, el hombre que porta la dosis personal de marihuana tiene en su mente la proposición: "La Corte Constitucional consideró no penalizable portar menos de veinte gramos de marihuana" (p), además, el hombre cuenta en su mente con la proposición: "Lo que diga la Corte Constitucional debe ser acatado por los policías" (q), por lo que, finalmente, el hombre le asevera al policía: "Usted no puede detenerme" (r). Este caso, y junto a él, otro número humanamente incalculable, muestra la manera como muchas proposiciones son afirmadas o negadas. Así, varias son afirmadas o negadas porque están respaldadas por otras proposiciones. El hombre motiva su afirmación (r), en las proposiciones 
(p) y (q). Cuando un grupo de proposiciones por su respaldo y peso arrastran a afirmar otra $u$ otras se está ante el acto humano de argumentar. Brevemente, argumentar es respaldar una o varias proposiciones en otras proposiciones.

En su Curso de argumentación jurídica (2013) Manuel Atienza señala que la argumentación es la actividad esencial de los juristas en los Estados constitucionales. En razón a que el derecho cada vez más se ve como una actividad y no como un conjunto fijo de contenidos, y a que actualmente se vive un declive al seguimiento de la autoridad y de la tradición, la actividad de la argumentación es el lugar común de los sistemas jurídicos. Independiente de la actitud que se tenga hacia el derecho, ya sea la de iusnaturalista o el positivista jurídico, la argumentación enlaza a los juristas de distintos credos en una sola familia. Como las proposiciones y sus principios lógicos permiten la correcta construcción de argumentos, estos son la sangre que corre en el sistema del derecho. Solo hay argumentos en tanto existan proposiciones, y estas, están unidas por ciertos tipos de relaciones lógicas que permiten en su correcta conexión la formación de argumentos válidos. Así, en un argumento, además de proposiciones, existe una estructura lógica que permite la adecuada ilación entre ellas.

\section{Forma y contenido de los argumentos}

En la sentencia de constitucionalidad C-87 de 1998 el ponente Carlos Gaviria argumentó que la actividad que realizan los periodistas, no debe restringirse solo aquellos que tengan título de periodistas o de comunicadores. En tanto la esencia del ejercicio del periodismo es informar y hacer uso de la libertad de opinión, cualquier ciudadano puede ejecutar este tipo de actividad, Gaviria argumentó que:

Premisa 1: Todo derecho fundamental es algo que debe privilegiarse en los Estados democráticos.

Premisa 2: Toda libertad de opinión es un derecho fundamental.

Por lo tanto: Toda libertad de opinión es algo que debe privilegiarse en los Estados democráticos.
Este argumento consta de tres proposiciones, de las cuales, dos son premisas y una es conclusión. Las premisas son aquellas proposiciones que respaldan o arrastran a afirmar la otra, esta última es la conclusión. Así, la proposición: la libertad de opinión es algo que debe privilegiarse en los Estados democráticos, está justificada en las proposiciones: todo derecho fundamental es algo que debe privilegiarse en los Estados democráticos, y la libertad de opinión es un derecho fundamental. Estas tres proposiciones muestran además el contenido del argumento. Esto es, aquello de lo que específicamente trata el argumento: Derechos fundamentales, libertad de opinión y lo que privilegia los Estados democráticos. Adicional a ello, el argumento tiene una forma, esto es, una estructura en la que se presentan el conjunto de proposiciones.

La primera proposición dice: Todo derecho fundamental es algo que debe privilegiarse en los Estados democráticos. Si simbolizamos el concepto Derecho fundamental con la letra $\mathrm{M}$, y lo que debe privilegiarse en los Estados democráticos con la letra $\mathrm{P}$, tenemos que la primera proposición afirma: Todo $\mathrm{M}$ es $\mathrm{P}$. En la segunda premisa podemos simbolizar: Libertad de opinión por la letra $\mathrm{S}$, con lo que la segunda premisa afirma: Todo $\mathrm{S}$ es M. La conclusión, aquello que se apoya en las premisas, simbólicamente afirma: Todo S es P.

Premisa 1: Todo M (derecho fundamental) es $\mathrm{P}$ (algo que debe privilegiarse en los Estados democráticos).

Premisa 2: Toda S (libertad de expresión) es M (derecho fundamental).

Conclusión:

Toda S (libertad de expresión) es P (algo que debe privilegiarse en los Estados democráticos).

Así, la estructura del argumento es:

Premisa 1: Todo $\mathrm{M}$ es $\mathrm{P}$

Premisa 2: Todo S es M

Conclusión: Todo S es P

Este esquema argumentativo es conocido como silogismo. Esto es, una estructura de argumento 
que consta de dos premisas y una conclusión, y que presenta como forma de contenido tres conceptos, los respectivamente simbolizados por las letras $\mathrm{S}, \mathrm{P}, \mathrm{M}$. No es la única forma silogística argumentativa, pero si es una buena representación de aquello que se conoce como forma o estructura de los argumentos. Al ser forma, esta estructura puede llenarse con contenido. Sea de tipo jurídico o de cualquier otra naturaleza, siempre que pueda seguir la forma de afirmación de las tres proposiciones.

El siguiente argumento, a pesar de que trata de un tema distinto al jurídico mantiene la misma forma silogística:

Premisa 1: Todas las especies de animales que amamantan a sus crías son mamíferos.

Premisa 2: Todas las ballenas son especies de animales que amamantan a sus crías.

Conclusión: Todas las ballenas son mamíferos.

La forma se mantiene pues:

Premisa 1: Toda M (especie animal que amamantan a sus crías) es $\mathrm{P}$ (mamífera).

Premisa 2: Toda S (ballena) es M (especie animal que amamanta a sus crías).

Conclusión:

Toda S (ballena) es P (mamífero).

Así, la estructura del argumento es:

Premisa 1: Todo M es P

\section{Premisa 2: Todo S es M}

Conclusión: Todo S es P

La misma estructura argumentativa silogística podría servir para apoyar una idea contraria al sentido de la sentencia de constitucionalidad C-87 de 1998. Como se mencionó, el fallo aprueba que las personas que no tienen el título profesional de periodistas puedan ejercer este oficio. Sobre la base de la libertad de opinión, se aprueba que el trato con la información y su difusión no es exclusividad de uno pocos. No obstante, bajo el principio fundamental de que el Estado debe garantizar la seguridad nacional (Artículo 2 de la Constitución) bien podría construirse un argumento que tuviese la misma estructura, pero que llegará a una conclusión distinta al espíritu de la Sentencia C-87 DE 1998:

Premisa 1: Todo lo que genere peligro para la estabilidad social es algo que debe ser regulado por el Estado.

Premisa 2: Toda libertad de expresión es algo que genera peligro para la estabilidad social.

Conclusión: Toda libertad de expresión es algo que debe ser regulada por el Estado.

Al final tenemos la misma estructura

Premisa 1: Todo $\mathrm{M}$ es $\mathrm{P}$

Premisa 2: Todo S es M

\section{Conclusión: Todo S es P}

El primer argumento, al que podemos llamar Argumento de la libertad de expresión, tiene la misma estructura de este último, al que podemos llamar Argumento de la censura de expresión. Así, tanto la libertad de expresión como la censura de expresión pueden defenderse racionalmente partiendo de la misma estructura argumentativa silogística. Independientemente de la afiliación por uno u otro argumento la estructura es igual, por lo que la forma del silogismo es irrelevante en relación con el contenido que desee otorgársele. Esta distinción entre forma y contenido es fundamental para comprender agudamente la argumentación, y específicamente, para reconocer los alcances de la lógica en el ejercicio de la argumentación y del derecho.

La distinción entre forma y contenido obliga a utilizar con precisión las parejas de palabras: válido e inválido, verdad y falsedad, que son los términos con los que en lógica se suelen evaluar dos propiedades de los argumentos. No es un asunto de estilo o de capricho el uso de estas palabras. Hay sendas distinciones entre los objetos o referencias que comprenden. La validez es el predicado que se le otorga a una estructura lógica que está correctamente armada, una 
forma silogística en la que la conclusión se deriva de las premisas. La validez se refiere a una organización compleja conformada por proposiciones, unas de ellas premisas y otras conclusiones. La estructura silogística: premisa 1 . Todo $\mathrm{M}$ es $\mathrm{P}$; premisa 2 . Todo $\mathrm{S}$ es $\mathrm{M}$; y conclusión Todo $\mathrm{S}$ es $\mathrm{P}$, como vimos en los ejemplos de arriba, es una estructura silogística válida. Esto porque la conclusión se deriva de las premisas. Independientemente del tema que trate: libertad de expresión, Estados democráticos, ballenas, mamíferos, censura del Estado, estabilidad social, y un interminable etc. En tanto la conclusión se deriva de las premisas se predica de la forma argumentativa que es válida.

En el caso de la verdad y falsedad estas dos palabras se aplican no a la estructura argumentativa, sino al contenido que se presenta en cada una de las proposiciones. Decir: “Todas las especies de animales que amamantan a sus crías son mamíferos" es una afirmación verdadera o falsa; lo mismo puede decirse de proposiciones como: las ballenas son mamíferos; toda libertad de expresión es algo que genera peligro para la estabilidad social; la libertad de expresión es un derecho fundamental, etc. Así, en la argumentación un aspecto relevante es la forma o estructura, y otro distinto es el contenido. La estructura, rasgo que se evalúa como válido o inválido es de importante atención para la lógica, mientras que el contenido es de cuidado para los especialistas de cada materia. Un biólogo prestará importante atención al hecho de que las ballenas sean mamíferas, algo parecido puede esperarse de un jurista ante la proposición: la libertad de expresión es algo que debe ser regulado por el Estado. Mientras que la relación de inferencia entre proposiciones, la correcta conexión entre las premisas y conclusiones, convoca no el espíritu especialista del que argumenta, sino sus destrezas de consistencia lógica. La forma como la estructura de los argumentos y el contenido como la información con la que se llena una estructura argumentativa, señalan dos aspectos distintos y necesarios para la construcción de argumentos. Válido o inválido son los términos con los que se evalúa la forma, y verdadero o falso son los vocablos con los que se evalúa el contenido o información de los argumentos.

\section{El silogismo}

Los silogismos son estructuras o formas argumentativas conformadas necesariamente por tres proposiciones, de las cuales dos son premisas y una es conclusión. Si un argumento tiene más de dos premisas o más de una conclusión no es un silogismo. Además de esto, sus tres proposiciones necesariamente tienen tres términos, estos es, están conformadas por tres conceptos. Los conceptos de los silogismos se reconocen con las palabras o los símbolos con los que se arman las proposiciones. Así, en el que hemos llamado Argumento de la libertad de expresión, los tres términos de los silogismos son: 1. Derecho fundamental; 2. Algo que debe privilegiarse en los Estados democráticos, y 3. Libertad de expresión. En símbolos, los tres términos de este silogismo son $\mathrm{M}$, $\mathrm{P}, \mathrm{S}$. Aunque el argumento tiene tres proposiciones, estos tres términos son los que definen el contenido específico del silogismo; las tres proposiciones se configuran con estos tres conceptos. Las palabras todo y es, no son términos de los silogismos, porque no se refieren al contenido especial del que trata el argumento. Las palabras: todo, o todas o todo, operan como cuantificadores de las proposiciones, pero no como términos. La palabra: es, conecta los términos, pero no es un término del silogismo. El argumento de La libertad de expresión cumple con los requisitos: dos premisas y una conclusión, y tres términos.

Premisa 1: Todo derecho fundamental es algo que debe privilegiarse en los Estados democráticos.

Premisa 2: Toda libertad de opinión es un derecho fundamental.

Por lo tanto: Toda libertad de opinión es algo que debe privilegiarse en los Estados democráticos.

Adicional a lo anterior, en los argumentos silogísticos la conclusión se deriva completamente de las premisas. Esto es, dadas las premisas la conclusión necesariamente se sigue de ellas. Ello, porque en este tipo de argumento, la conclusión está plenamente contenida en las premisas, así que, dadas las premisas, la conclusión se infiere necesariamente. En un argumento silogístico no puede ser que se acepta que sus premisas son verdaderas, que la conclusión se deriva de ellas, pero que la conclusión es falsa. $\mathrm{Si}$ 
las premisas son verdaderas y la conclusión se deriva completamente de las premisas, la conclusión también es verdadera. Esta propiedad de que la conclusión se deriva completamente de las premisas puede verse mejor representada en un gráfico. Tomemos la forma silogística del argumento anterior y representemos cada uno de los términos con círculos:

Premisa 1: Todo $\mathrm{M}$ es $\mathrm{P}$

Premisa 2: Todo $\mathrm{S}$ es $\mathrm{M}$

Conclusión: Todo S es P
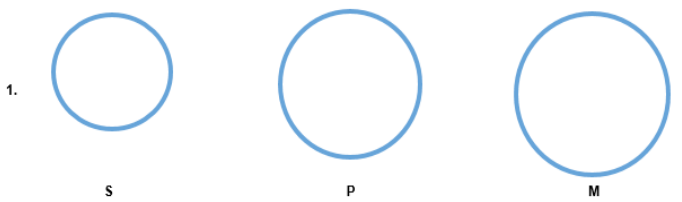

Cuando la primera premisa dice Todo $\mathrm{M}$ es $\mathrm{P}$, podría dibujarse como:

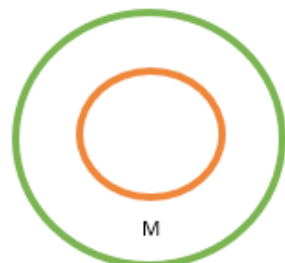

P

Cuando la segunda premisa dice, Todo $\mathrm{S}$ es $\mathrm{M}$, y teniendo en cuenta el diagrama anterior, podría dibujarse como:

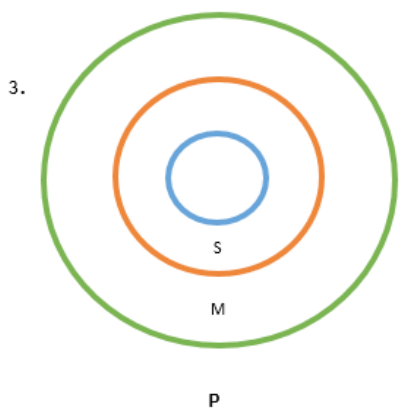

Puede verse que la conclusión: Todo $\mathrm{S}$ es $\mathrm{P}$, se sigue necesariamente de las premisas. Así, si Todo M es P, y Todo S es M, necesariamente todo S es P. Aristóteles en sus Tratados de lógica (1979) presenta el primer estudio sistemático de la estructura argumentativa silogística. Con el nombre Primeros Analíticos describe la relación de inferencia que se da entre las premisas y conclusiones en este tipo de argumentos, en los que su condición esencial es, como se mencionó: consta de tres proposiciones, de las cuales dos son premisas y la otra es conclusión; contiene tres términos, y la conclusión se sigue necesariamente de sus premisas.

\section{El silogismo jurídico y sus críticas}

Dada la siguiente descripción general de lo que es un silogismo, puede entenderse fácilmente qué es un silogismo jurídico. Una vez establecida la diferencia entre forma y contenido, un silogismo jurídico es aquel tipo de argumento en el que sus premisas contienen información jurídica, específicamente, una de sus premisas puede interpretarse como una norma, y la otra como un hecho al que es pertinente evaluarse con la norma; la conclusión, es lo que se sigue necesariamente una vez establecido el contenido de las premisas. Como en toda forma silogística, una norma singular, un hecho específico no constriñe la noción de silogismo jurídico. Esto es, para que algo sea considerado como tal, no tiene que otorgársele como contenido unas normas específicas o unos acontecimientos específicos.

La noción de forma o estructura silogística permea a los silogismos jurídicos, permitiéndoles múltiples interpretaciones. De hecho, las normas jurídicas no son estáticas, por lo que el contenido de la premisa que contiene la norma tampoco puede considerarse inmóvil. Igual ocurre con los hechos que pueden reclamar evaluación jurídica, estos son innumerables, en esencia, todos aquellos, ya sean del pasado, presente y futuro en el que los intereses de uno afecten jurídicamente los de otro. De ahí que la multiplicidad de contenido que una estructura silogística pueda tener es similar a la que se puede presentar en los silogismos jurídicos. Así, independientemente de la ideología que eventualmente pueda estar en el corazón de cierto tipo de normas o proposiciones jurídicas, una forma silogística puede testarse con 
posiciones jurídicas que difieran en sus presupuestos fundamentales. Puede tenerse un silogismo jurídico que convoque una norma que tenga como doctrina la idea de que debe privilegiarse hasta donde más se pueda la autonomía de las personas; igualmente, puede armarse un silogismo jurídico que tenga como credo la necesaria sumisión de los individuos a los preceptos colectivamente aceptados, independientemente de si son justos o injustos.

A pesar de la abierta posibilidad de interpretación de los silogismos jurídicos, y de la naturaleza esencialmente formal de los argumentos silogísticos, es corriente la crítica a esta forma de razonamiento, en especial, cuando se instaura en el campo del derecho. Citando al filósofo del derecho Luis Recaséns, Manuel Atienza (2013) recoge en una muy buena síntesis de la crítica a que ha tenido lugar el uso de estructuras lógicas formales y matemáticas, las que incluye el silogismo y su empleo en la argumentación jurídica. Dice Recaséns citado por Atienza:

Ahora bien, la lógica tradicional o físicomatemática no es adecuada para tratar la vida humana ni sus problemas prácticos, por consiguientes, tampoco para los menesteres jurídicos, entre los cuales figura la interpretación del Derecho. -Hay que emplear un tipo diferente del logos, que tiene tanta dignidad como la lógica tradicional, si es que no es superior a la de esta: hay que manejar el logos de lo humano, la lógica de lo razonable, la cual es razón, tan razón como la lógica de lo racional, pero diferente de esta. (Atienza, 2013:264).

Sobre el supuesto de que el derecho no es la estructura sistemática y normativa que los positivistas jurídicos están dispuestos a defender, pues el orden jurídico no es llanamente un sistema cerrado de normas y de relaciones lógicas, los críticos de la formalidad lógica en el derecho, suelen apelar a la necesidad de ver el derecho como una textura teórica abierta. Los razonamientos jurídicos deben estar impregnados de experiencias pasadas, de principios y valores, de todo el conocimiento que la vida misma y su almacenamiento en la historia puede dispensar. Por esto el silogismo, y su variante formal como silogismo jurídico desvía la práctica real y sensata del derecho.
Este tipo de crítica que busca extirpar la lógica formal, al silogismo y su uso jurídico, puede reprobarse una vez que se muestra que obedece a una serie de confusiones con respecto a lo qué es argumentar, específicamente, a lo que son la forma o estructura de los argumentos. Como se mostró al inicio de este documento, independiente de la posición que se tome con respecto a lo que es la esencia del derecho: ya sea como un sistema de normas a las que debe subordinarse los sujetos, positivismo jurídico, o como el tipo de práctica social que tiene a la justicia como su idea reguladora, iusnaturalismo, en tanto unos y otros aceptan la argumentación como esencia del ejercicio del derecho, convienen en la necesaria constitución proposicional del derecho. Como saber teórico o como ejercicio argumentativo, el derecho está compuesto de proposiciones. Estas se vinculan a través de relaciones lógicas de inferencia y justificación. Sin importar el contenido o la información volcada en las proposiciones, estás siguen relaciones lógicas de conexión. Y una cosa es la proposición y la información que en ella se soporta, y otra muy distinta es la forma o estructura lógica de las proposiciones y sus relaciones lógicas. El silogismo jurídico está del lado de la forma, es una de las múltiples estructuras en las que una serie de proposiciones se presentan.

\section{Conclusiones}

Criticar el silogismo jurídico es enjuiciar una forma o estructura de argumentación válida. No obstante, el iusnaturalismo y el positivismo jurídico son posiciones que se refieren a los principios esenciales, a las verdades fundamentales que deben abrazarse en el derecho. Su disputa no es un asunto de las formas argumentativas de las que puede echar mano el derecho, sino sobre lo que debe en esencia definir el derecho. Por lo tanto, la discusión sobre el silogismo jurídico y el uso de la lógica formal en el derecho no vincula necesariamente a uno $\mathrm{u}$ otro punto de vista.

De otro lado, la crítica a la lógica y a sus estructura formales, como son las silogísticas, sobre la base de que no tienen en cuenta las vidas singulares de las personas, los valores, principios y el conocimiento que los contextos que la realidad dispensa a los juristas, 
igualmente confunde la forma con el contenido. Una estructura silogística puede servir para argumentar porqué es relevante para el derecho las circunstancias específicas de los sujetos y no el simple imperio de la ley. De igual manera, una estructura silogística puede servir para argumentar que toda actividad jurídica debe incluir valores como la justicia o el bien para su realización. En tanto las formas argumentativas pueden usarse para justificar cualquier tipo de contenido: defender principios, valores o normas, ellas pueden legítimamente ser silogismos. El escritor portugués Gonzalo Tavares afirma que "La ley está al servicio del bien y del mal", esto porque las leyes son los instrumentos con los que se busca dirigir cierto tipo de conductas. Históricamente algunas leyes han conducido a la decadencia de algunas sociedad, otras al florecimiento de lo humano. No obstante, las leyes como instrumentos no son ni buenas ni malas, simplemente buscan conducir la vida de las personas a partir de lo que en ellas se establece. El hecho de que ciertas leyes hayan causado dolor en la vida humana, no significa que deban eliminarse. Igual sucede con la forma de los argumentos. Los silogismos jurídicos son uno de los instrumentos que sirven para gestionar correcta o inadecuadamente los sistemas jurídicos. Si bien, en algunas ocasiones se han utilizado de manera inapropiada, no por ello debe descartarse o satanizarse su uso en el derecho.

\section{Referencias bibliográficas}

Agudelo, C. (2008) El uso de la palabra derecho: Un ataque a la práctica del silogismo judicial. En, Jurídicas. Revista de la Universidad de Caldas. N.2 Julio Diciembre, p. 71.88.

Aristóteles. (1979). Tratados de lógica. México. Porrúa.

Atienza, M. (2013). Curso de argumentación jurídica. Madrid: Trotta.

Austin, J. (1971). Palabras y acciones. Buenos Aires: Paidós.

Bobbio, N. (1997). El problema del positivismo jurídico. México: Fontamara.

(2007). Teoría general del derecho. Bogotá: Temis.
Borges, J. (2013). Poesía completa. Bogotá: Debolsillo.

Gaviria, C. (2002). Sentencias, herejías constitucionales. Bogotá: Fondo de Cultura Económica.

Tavares, G. (2012) Entrevista realizada en el Diario el País. En: http:/cultura. elpais.com/cultura/2012/03/12/ actualidad/1331540617_145557.html

Hobbes, T. (1994). Leviatán. México: Fondo de Cultura Económica.

Kant, I. (2006). Crítica de la razón pura. México: Taurus.

Kelsen, H. (1998) ¿Qué es la teoría pura del derecho? México: Fontamara.

Lask, Emil. (2008). Filosofía jurídica. Buenos Aires: BdeF.

Vélez, B. (2014) A propósito de las reformas en la educación y la necesidad de una reivindicación de la pluralidad. Sophia, Vol 10 \#2. Armenia: Universidad la Gran Colombia.

Wittgenstein, L. (1988). Investigaciones filosóficas. Barcelona: UNAM. 